\title{
Adrenal Cortex Adenoma
}

National Cancer Institute

\section{Source}

National Cancer Institute. Adrenal Cortex Adenoma. NCI Thesaurus. Code C9003.

A benign neoplasm that can arise from any of the adrenal cortical layers. It can be associated with the overproduction of glucocorticoids (Cushing's syndrome), androgenic or estrog enic steroids (adrenogenital syndrome), or mineralocorticoids (Conn's syndrome). (Sternberg Diagnostic Surgical Pathology, 3rd ed.) 